\title{
ANÁLISE COMPARATIVA DA RESISTÊNCIA À COMPRESSÃO SIMPLES DE CORPOS-DE-PROVA, TIJOLOS E PAINÉIS DE SOLO-CIMENTO
}

\author{
Mário Monteiro Rolim¹ , Wesley Jorge Freire ${ }^{2}$ e Antonio Ludovico Beraldo ${ }^{3}$
}

\begin{abstract}
RESUMO
Dentre as muitas utilizações do solo-cimento, destaca-se seu uso na fabricação de tijolos de alvenaria. Neste trabalho, um solo arenoso contendo $72 \%$ de areia, foi tratado com $8 \%$ de cimento Portland, em relação ao peso do solo seco, sendo com a mistura moldados corpos-de-prova cilíndricos de 10 x $12,73 \mathrm{~cm}$, de diâmetro e altura, respectivamente, tijolos de dimensões 5 x 11 x $23 \mathrm{~cm}$, e um painel de alvenaria de $60 \times 60 \mathrm{~cm}^{2}$. Os tijolos de solo-cimento foram moldados em prensa manual, e o painel, construído com nove fiadas de tijolos, sendo instrumentado para medição das deformações. A resistência apresentada pelos tijolos de solo-cimento satisfez os requisitos exigidos pelas normas; por outro lado, no painel de alvenaria de tijolos de solo-cimento, as primeiras fissuras apareceram sob carregamento de $0,91 \mathrm{MPa}$, rom pendo-se o mesmo, de forma frágil, sob uma tensão próxima de 2,0 MPa.
\end{abstract}

Palavras-chave: solo-cimento, elementos construtivos, resistência

\section{COMPARATIVE STRENGTH ANALYSIS OF SPECIMENS, BRICKS, AND PANEL MOLDED BY SOIL-CEMENT}

\begin{abstract}
Soil-cement brick manufacture is one of the most common use of soil-cement material. In this work, a sandy soil (72\% sand content) was treated with $8 \%$ of Portland cement, on weight basis, and with the mixture were molded cylindrical specimens of $10 \times 12,73 \mathrm{~cm}$ in diameter and height, respectively, along with standard size bricks, and one $60 \times 60 \mathrm{~cm}$ masonry panel were molded The soil-cement bricks were molded in a manual operated machine and the soil-cement panel was constructed with nine layers of bricks provided with external devices for stress measurement. The results showed that soil-cement bricks were strong enough to meet the minimum Brazilian code requirements. On the other hand, soil-cement panel presented the first cracks when $0.91 \mathrm{MPa}$ tension was applied, breaking to rupture close to $2.0 \mathrm{MPa}$.
\end{abstract}

Key words: soil-cement, constructive element, strength

\section{INTRODUÇÃO}

O uso do solo-cimento para fabricação de tijolos vem sendo pesquisado no Brasil desde há muito tempo, constituindo-se ele um dos elementos principais da construção com terra, daí a necessidade de se conhecer os materiais utilizados, principalmente o solo, que deve ser física e mecanicamente caracterizado; por isto, este trabalho teve como objetivo estudar a resistência à compressão simples do material solo-cimento,

\footnotetext{
${ }^{1}$ Prof. Assistente, DTR/UFRPE, Rua Dom Manoel de Medeiros S/N, Dois Irmãos, Recife, PE, CEP 52171 - 900 . Doutorando FEAGRI/ UNICAMP

${ }^{2}$ Prof. Titular, FEAGRI/UNICAMP, Cidade Universitária “Zeferino Vaz”, Barão Geraldo, Campinas, SP, CP 6011, CEP 13083-970

${ }^{3}$ Prof. Assistente Dr, FEAGRI/UNICAMP
} 
determinada experimentalmente em corpos-de-prova, tijolos e painéis de alvenaria, analisando-se a deformabilidade.

Segundo a ABCP (1985), os solos mais arenosos são os que se estabilizam com menores quantidades de cimento, sendo necessária a presença de argila na sua composição, visando dar, à mistura, quando umedecida e compactada, coesão suficiente para a imediata retirada das formas.

A possibilidade de utilização de solo do próprio local constitui-se numa das grandes vantagens do solo-cimento, sendo que, na mistura solo-cimento, o solo é o elemento que entra em maior proporção, devendo ser tal que permita o uso da menor quantidade possível de cimento.

No que se refere às argamassas de assentamento, Sabbatini (1986) afirmou que, contrariamente às argamassas constituintes dos concretos, em que a característica desejável é basicamente a resistência mecânica, às de assentamento são fundamentais as características de trabalhabilidade, aderência e deformabilidade (quando endurecida).

No tocante a painéis de alvenaria, Mattone et al. (1995) utilizaram, para verificação da resistência à compressão simples de alvenaria de solo-cimento, painéis de 90 × $90 \mathrm{~cm}^{2} \mathrm{de}$ dimensões, com base de $60 \mathrm{~cm}$ para medições das deformações. Medindo a variação de distância entre os pratos da prensa, com o auxílio de extensômetros, para a medição de deformações de tijolo, Barbosa \& Mattone (1996) afirmaram que a deformação apresentada não correspondeu exatamente à do material, uma vez que, na zona de contato da prensa com as faces dos tijolos, ocorrem danos localizados e acomodações que ampliam as deformações.

Sousa et al. (1996) utilizaram painéis de tijolo de solo-cimento de dimensões $92 \times 98 \mathrm{~cm}^{2}$, no ensaio de resistência à compressão usando, para o registro dos deslocamentos verticais e horizontais, quatro extensômetros; na base do painel, os autores se valeram de borracha para a liberação dos deslocamentos horizontais.

A resistência dos tijolos é a grande responsável pela resistência da alvenaria; esta aumenta modestamente com o aumento da resistência da argamassa, mas cresce consideravelmente com a resistência dos tijolos (Franco, 1988). Este mesmo autor relembrou que a resistência da alvenaria aumenta com a resistência do tijolo, porém não linearmente, e que a resistência da alvenaria é proporcional à raiz quadrada da resistência dos tijolos.

Fator importante ressaltado por Franco (1988) é o que se refere à resistência à tração dos tijolos pois, quando a alvenaria é submetida à compressão uniforme, a ruptura se dá pelo desenvolvimento de fissuras, devido aos esforços de tração nos tijolos, transversais ao esforço de compressão aplicado. A argamassa, por sua vez, geralmente menos rígida que os tijolos, tende a deformar-se transversalmente, quando submetida a esforços de compressão. O movimento da argamassa é restringido pelos tijolos, que ficam submetidos à tensão de tração lateral levando, inicialmente, à fissuração e, finalmente, à ruptura. Hoath, citado apud (1988), afirmou que uma argamassa com cal, comparada com a de cimento, sendo ambas de resistência equivalente, produz paredes de maior resistência à compressão e atribuiu este fato ao maior potencial de aderência das argamassas de cal.

\section{MATERIAIS E MÉTODOS}

O trabalho foi conduzido no Laboratório de Ensaio de Materiais da Faculdade de Engenharia Agrícola e no Laboratório de Estruturas e Materiais da Faculdade de Engenharia Civil, ambas da Universidade Estadual de Campinas, SP.

$\mathrm{O}$ solo arenoso estudado foi classificado como solo $\mathrm{A}_{2-4(0)}$, pelos critérios da AASHTO, e pertence à classe textural arenosa, segundo o Bureau of Public Roads, estando suas principais características apresentadas na Tabela 1.

Foram utilizados, no experimento, o cimento Portland $\mathrm{CP}$ II-E-32 e a cal, ambos da marca VOTORAN.

Os corpos-de-prova cilíndricos e os tijolos fabricados com solo-cimento foram rompidos em prensa VERSA TESTER com capacidade máxima de $15.000 \mathrm{kgf}$ e sensibilidade de $25 \mathrm{~kg}$. A prensa dispunha, ainda, de dispositivo de controle de velocidade de carregamento.

Os tijolos de solo-cimento foram moldados com o auxílio de máquina de fabricação de tijolos marca SOLOTEST, de acionamento manual, para compactação da mistura fresca e cuja capacidade de fabricação é de três tijolos por prensagem, tijolos do tipo II, de acordo com a norma NBR-08492 (1984) da ABNT.

$\mathrm{O}$ pórtico utilizado tinha capacidade para $500 \mathrm{kN}$, sendo a medição das cargas efetuada com o auxílio de uma célula de carga e as deformações medidas através de defletômetros mecânicos, com base de $40 \mathrm{~cm}$ para o painel e $5 \mathrm{~cm}$ para os corpos-de-prova.

Em todos os casos, utilizou-se a fração de solo passante na peneira ABNT no 4 (abertura de malha igual a 4,76 mm) sendo as amostras de solo secas ao sol e peneiradas, antes de serem tratadas com $8 \%$ de cimento, em relação ao peso do solo seco, dose indicada pelo método simplificado de dosagem de misturas de solo-cimento; as misturas foram homogeneizadas e, antes de serem ensaiadas, tiveram o seu teor de umidade controlado.

Tabela 1. Características do solo arenoso estudado

\begin{tabular}{clc}
\hline Composição & Areia grossa $(0,42-2,00 \mathrm{~mm})$ & 4,0 \\
textural & Areia fina $(0,05-0,42 \mathrm{~mm})$ & 68,0 \\
(\% em peso) & Silte $(0,005-0,05 \mathrm{~mm})$ & 11,0 \\
& Argila $(<0,005 \mathrm{~mm})$ & 17,0 \\
Limites de & Limite de liquidez & 15,3 \\
consistência & Limite de plasticidade & 14,4 \\
$(\%)$ & Índice de plasticidade & 0,9 \\
Classificação & AASHTO & $\mathrm{A}_{2-4(0)}$ \\
& Bureau of Public Roads & Arenoso \\
Características & pH (em CaCl $)$ & 4,40 \\
químicas & Matéria orgânica $(\%)$ & 1,60 \\
\hline
\end{tabular}

As amostras de solo destinadas à confecção dos tijolos de solo-cimento, após mistura com cimento e adequada homogeneização, recebiam água em quantidade necessária para elevar o seu teor de umidade até o da umidade ótima do ensaio de compactação normal de Proctor, antes de serem prensados.

Os seguintes procedimentos metodológicos foram observados neste experimento:

- preparação das amostras de solo para os ensaios de 
caracterização e compactação, realizada de acordo com a norma NBR 06457 (1984);

- teor de umidade do solo e do solo-cimento, determinado pelo método da estufa a $105^{\circ} \mathrm{C}$, durante $24 \mathrm{~h}$;

- análise granulométrica, feita de acordo com a norma NBR 07181 (1984);

- limites de consistência, determinados de acordo com as normas NBR 0659 (1984) para o limite de liquidez, e NBR 07180 (1984) para o limite de plasticidade;

- ensaio de compactação, realizado de acordo com as normas NBR 07182 (1984) para o solo, e NBR 12023 (1990) para o solo-cimento;

- moldagem de corpos-de-prova cilíndricos de solo-cimento, feita de acordo com a norma NBR 12024 (1990);

- ensaios de compressão simples de corpos-de-prova cilíndricos de solo-cimento, realizados de acordo com a norma NBR 12025 (1990), e submetidos às mesmas condições que os tijolos, em termos de cura e idade de rompimento; os corposde-prova de solo-cimento foram capeados com enxofre apenas na face superior de trabalho.

Tanto os corpos-de-prova de argamassa de cimento:cal:solo, de dimensões 5 x $10 \mathrm{~cm}$, de diâmetro e altura, respectivamente, como o painel, foram simultaneamente moldados e igualmente rompidos aos 7 dias de idade.

Depois de prensados, os tijolos foram cuidadosamente extraídos das formas e deixados a secar ao ar livre e à sombra, por $12 \mathrm{~h}$ sendo, em seguida, empilhados e curados em câmara úmida, até serem ensaiados à compressão.

Quatro tijolos de solo-cimento, representativos do lote, foram aleatoriamente escolhidos, identificados e medidos. Os tijolos foram preparados de acordo com a norma NBR-08492 (1984), sendo serrados ao meio e superpostos, tendo suas faces ligadas com uma camada fina de pasta de cimento de 1 a $2 \mathrm{~mm}$ de espessura sendo, também, capeados com auxílio de uma espátula.

Um painel de $60 \times 60 \mathrm{~cm}^{2}$, com nove fiadas de tijolos de solocimento, foi também construído, seguindo-se recomendações de Collantes et al. (1994), no pórtico e no mesmo local em que seria realizado o ensaio de compressão simples. Dois blocos de concreto foram utilizados a fim de que a altura do painel, depois de pronto, ficasse convenientemente disposta na mesma altura da célula de carga.

Escolheu-se a argamassa de assentamento de cimento, cal e solo, de traço 1:1:5, em função das recomendações de Nascimento \& Helene (1988) e Franco (1988), pois para os autores, este tipo de argamassa minimiza os efeitos da fissuração.

Após confeccionado o painel, foi regularizada sua superfície com uma pasta de cimento; um perfil metálico foi utilizado para distribuição das cargas (Figura 1).

O painel foi instrumentado em três direções de deformação na vertical (para esforços de compressão, linhas 1-2, 3-4, 5-6) e uma na horizontal (para a medição de deformação resultante de esforços de tração, linha 7-8); em seguida, foram registradas as respectivas deformações e suas cargas, até o rompimento do painel.

Todos os ensaios foram conduzidos com três repetições, exceto aqueles aplicados aos corpos-de-prova de tijolos, que foram em número maior. O ensaio do painel não foi repetido, devido às dificuldades na montagem do experimento.

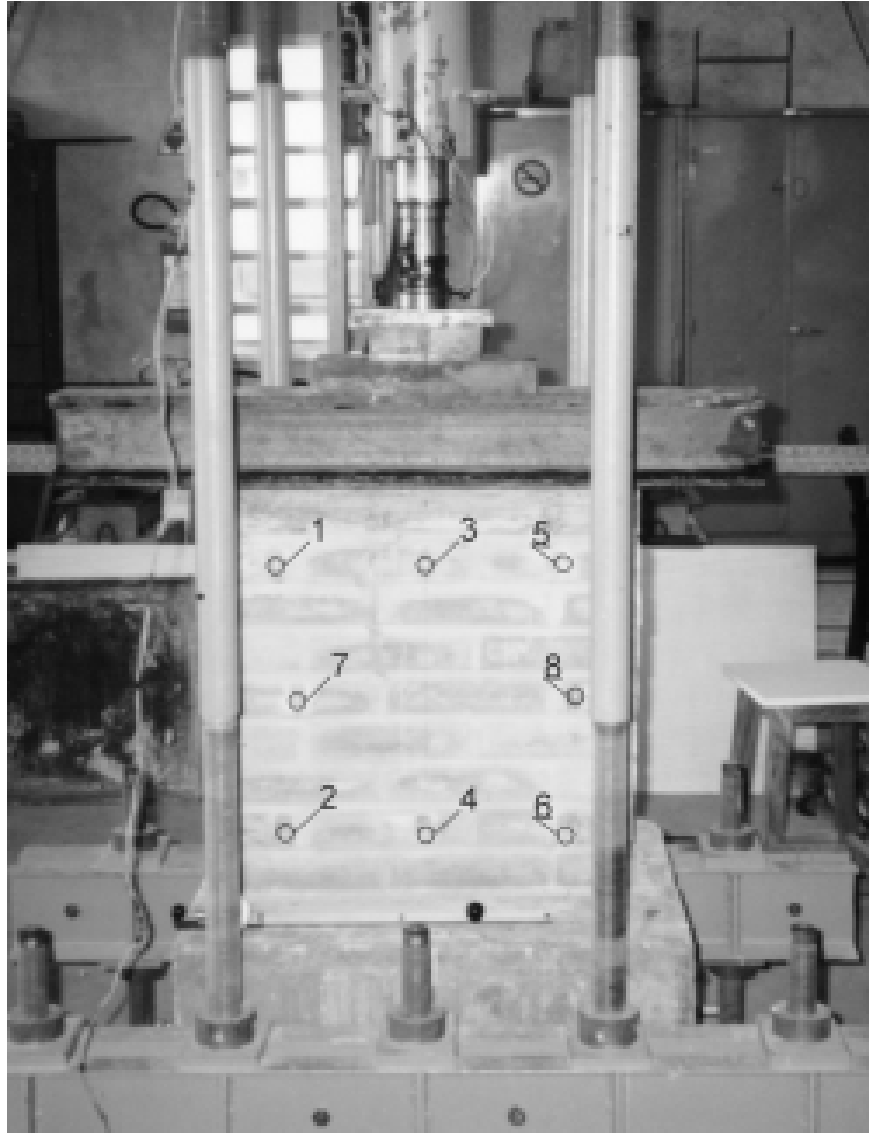

Figura 1. Painel de alvenaria de tijolos de solo-cimento antes de ser ensaiado

\section{RESULTADOS E DISCUSSÃO}

A massa específica aparente seca máxima do ensaio de compactação do solo-cimento foi igual a $19,60 \mathrm{kNm}^{-3}$ para uma umidade ótima de $11,45 \%$, valores condizentes para o solo arenoso $\mathrm{A}_{2-4}$ utilizado.

Os valores médios de resistência à compressão simples obtidos para corpos-de-prova cilíndricos de solo, de solocimento e de argamassa (cimento/cal/solo) foram, respectivamente, iguais a 1,43, 3,26 e 2,23 $\mathrm{MPa}$; para tijolos de solo-cimento de dimensões 5 x 11 x $23 \mathrm{~cm}$, confeccionados com solo arenoso tratado com $8 \%$ de cimento Portland, o valor médio de resistência à compressão simples foi igual a 2,2 $\mathrm{MPa}$

Da análise dos dados, pode-se observar que o valor da resistência à compressão simples dos corpos-de-prova apresentou ganho de resistência da ordem de $128 \%$ pela simples adição de cimento ao solo; os valores obtidos para a argamassa, por outro lado, foram considerados satisfatórios, uma vez que se procurou obter a máxima vantagem do parâmetro trabalhabilidade, e não propriamente da resistência do material em estudo. A resistência à compressão simples apresentada pela argamassa, aos sete dias, pode ser atribuída principalmente ao cimento, uma vez que o efeito da cal sobre a resistência, nesse período, é muito pequeno, não influenciando significativamente a resistência da alvenaria.

O valor médio obtido para a resistência à compressão simples dos tijolos de solo-cimento está de acordo com o disposto pela norma NBR-08492, que estabelece, como mínimo, o valor médio de 2,0 MPa, e nenhum valor inferior a 1,7 MPa. 
Como se pode observar, o valor da resistência à compressão simples dos tijolos de solo-cimento (2,2 MPa) está abaixo do valor obtido para corpos-de-prova de solo-cimento (3,26 MPa).

As Figuras 2, 3 e 4 mostram os resultados da instrumentação realizada nos corpos-de-prova cilíndricos de Proctor, nos corposde-prova de argamassa e nos tijolos de solo-cimento, respectivamente, apresentados na forma de diagramas tensãodeformação.

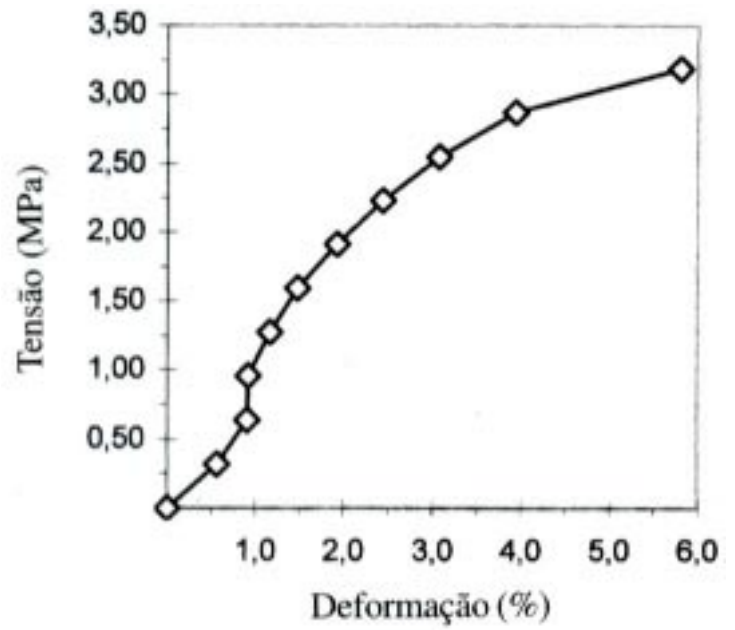

Figura 2. Diagrama tensão-deformação para corpos-de-prova cilíndricos de solo-cimento

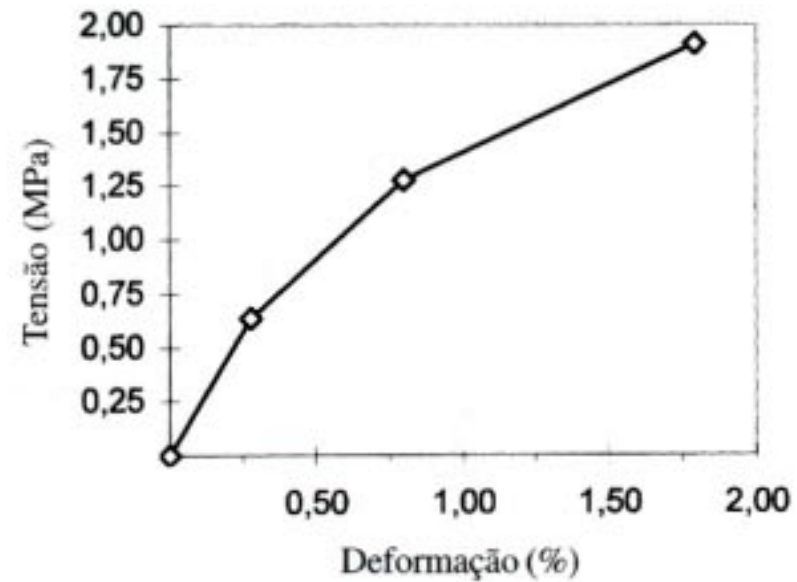

Figura 3. Diagrama tensão-deformação para corpos-de-prova de argamassa (1:1:5)

Os pontos de inflexão dos diagramas para os corpos-deprova cilíndricos de solo-cimento (Figura 2) e dos corpos-deprova de tijolos de solo-cimento (Figura 4), no trecho compreendido entre 0,5 e $1 \mathrm{MPa}$, estão de acordo com as conclusões de alguns autores que afirmaram haver certa acomodação entre o prato da prensa e a superfície do corpo-deprova durante o ensaio.

No que se refere às deformações relativas às tensões de compressão para o caso dos corpos-de-prova de solo-cimento, tijolos e argamassa, antes da ruptura, o maior valor de deformação foi obtido para os corpos-de-prova de tijolos de solo-cimento, enquanto o menor valor, foi obtido para os corposde-prova de argamassa. Tendo em vista as diferentes relações diâmetro/altura entre os corpos-de-prova de argamassa (1:2) e de solo-cimento (@ 1:1) e a geometria do tijolo,os estados de tensões a que os corpos-de-prova e os tijolos foram submetidos são diferentes; todavia, esses ensaios são normatizados e,

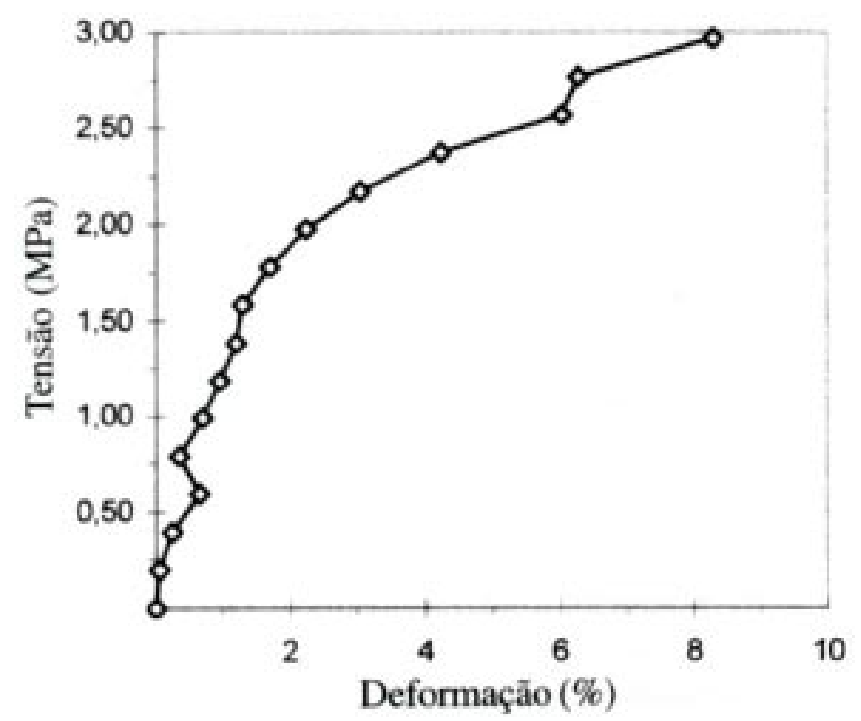

Figura 4. Diagrama tensão-deformação para corpos-de-prova de tijolos de solo-cimento

portanto, permitem comparações.

As Figuras 5 e 6 mostram, respectivamente, os resultados do ensaio de resistência à compressão simples do painel de alvenaria de tijolos de solo-cimento, para as três direções de deformações estudadas, e o diagrama de esforço de tração em função da mesma tensão aplicada.

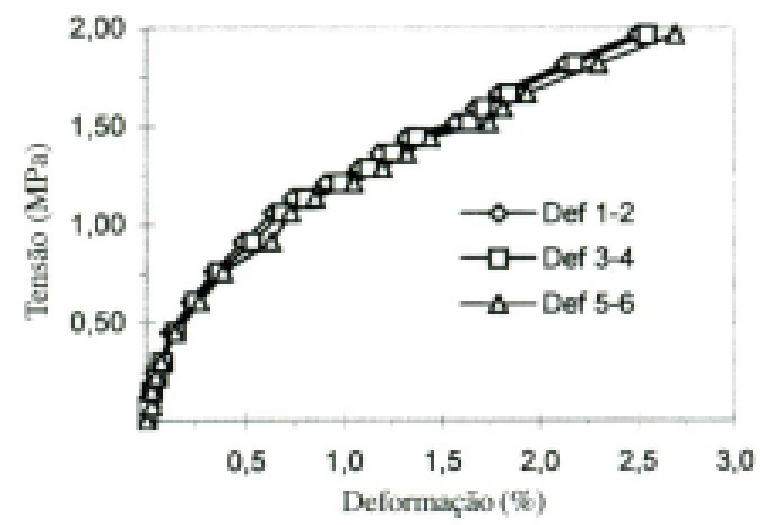

Figura 5. Diagrama tensão-deformação do painel de alvenaria de tijolos de solo-cimento, de dimensões de $60 \times 60 \mathrm{~cm}^{2}$ (esforços de compressão)

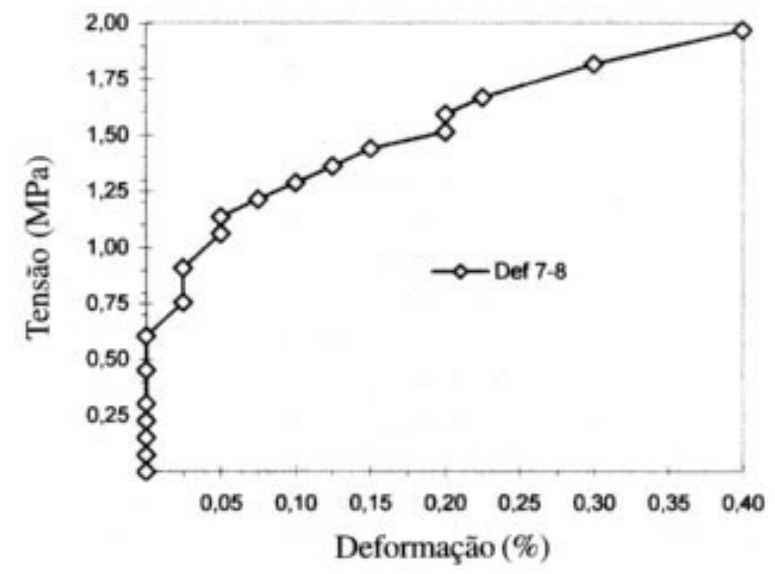

Figura 6. Diagrama tensão-deformação do painel de alvenaria de tijolos de solo-cimento dimensões de 60 x $60 \mathrm{~cm}^{2}$ (esforço de tração) 
A partir da análise dos diagramas apresentados, pode observar-se que:

- na linha de deformação Def 5-6 e para as mesmas tensões aplicadas, as deformações foram maiores, comprovando que, na região de maior fissuração ocorrerá, posteriormente, a ruptura e, conseqüentemente, a ruína da peça;

- até a tensão aplicada de $0,61 \mathrm{MPa}$, correspondente a aproximadamente $1 / 3$ da tensão de ruptura, a deformação de tração, medida, foi nula;

- as primeiras fissuras ocorreram sob tensões da ordem de 0,91 MPa (Figura 7), sendo que, para esta carga, ocorreu um começo de separação entre o tijolo e a junta de argamassa, desenvolvendo-se a fissura na direção vertical, paralelamente à direção da carga aplicada; para a alvenaria cerâmica, as primeiras fissuras ocorreram quando aproximadamente $50 \%$ da carga de ruptura foi aplicada;

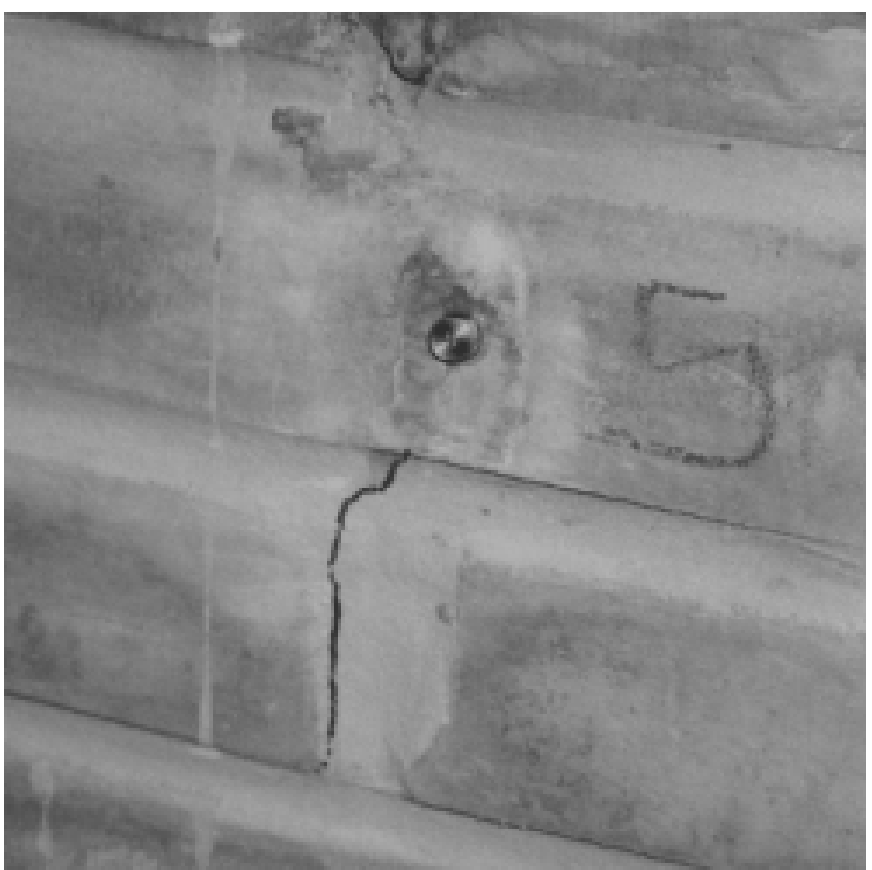

Figura 7. Painel, mostrando a ocorrência de fissuras

- com tensão de 1,14 MPa, teve início a ocorrência de fissuras em mais de um ponto, mas todas na direção vertical da junta de argamassa, provocadas por esforços de tração na alvenaria;

- com a tensão de 1,21 MPa, as fissuras começaram a desenvolver-se na direção horizontal ocorrendo, também, começo de separação entre o tijolo e a argamassa;

- a partir da tensão de 1,21 MPa não se fez mais medição contínua das deformações, por desconhecer-se o valor da carga de ruptura e por questão de segurança do experimento.

Os três valores de deformação de compressão medidos apresentaram-se muito próximos, levando a supor que houve boa centralização da carga em relação ao painel de alvenaria, demostrando uniformidade de resistência e de deformação, muito embora não se tenha verificado uniformidade na fabricação dos tijolos. A primeira fissura no tijolo ocorreu próximo à direção Def 5-6, direção esta relacionada à maior deformação.
A ordem de grandeza das tensões de ruptura nos vários elementos ensaiados foi a mesma, valor este próximo a 2,0 MPa. Instantes antes da ruptura foram observados estalos, provavelmente em decorrência da fissuração, rompendo-se o material de forma frágil, com uma grande explosão, fenômeno também observado por Franco (1988) para alvenaria cerâmica. O ângulo do plano de ruptura do painel foi de aproximadamente $60^{\circ}$ (Figura 8). De acordo com a fórmula de Haller, (Petrucci, 1987) e aplicada a alvenarias de tijolos cerâmicos maciços, terse-ia uma tensão predita $(\mathrm{R})$ igual a

$$
\mathrm{R}=0,7 \mathrm{MPa} \text {, para } \mathrm{Rtj}=2,08 \mathrm{MPa} \text { e } \mathrm{Rar}=2,23 \mathrm{MPa} .
$$

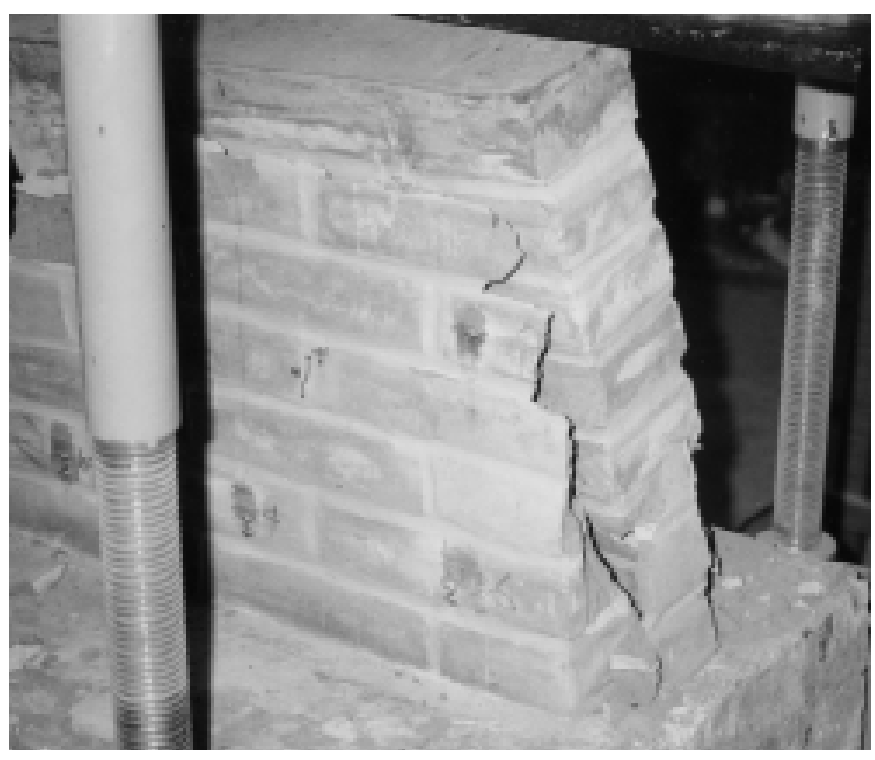

Figura 8. Painel após a ruptura

Da análise da Figura 8, que mostra a ruptura do painel de alvenaria de tijolos de solo-cimento, observa-se a forma de ruptura característica do cisalhamento do tijolo, evidenciandose, assim, a importância do elemento tijolo na alvenaria, tal como predito por Gobetti et al. (1994).

\section{CONCLUSÕES}

A partir da análise dos resultados obtidos do experimento, as seguintes conclusões podem ser obtidas:

- os resultados do ensaio de resistência à compressão de corpos-de-prova de solo-cimento com solo arenoso, tratado com $8 \%$ de cimento Portland, apresentaram valores superiores aos preconizados pela norma;

- da mesma forma, os valores de resistência à compressão apresentados pelos corpos-de-prova de tijolos de solo-cimento, atenderam aos requisitos estabelecidos pelas normas;

- o tempo decorrido entre a confecção do painel e o seu rompimento (7 dias) não foi condizente com a realidade, uma vez que os diversos elementos que compõem a alvenaria ganham resistência ao longo do tempo, o que é estabelecido pela prática;

- para ser estabelecida correlação entre os vários elementos estudados, recomenda-se a realização de um número maior de ensaios de painéis com diversos traços de argamassa. 


\section{REFERÊNCIAS BIBLIOGRÁFICAS}

ABCP. Fabricação de tijolos de solo-cimento com a utilização de prensas manuais. São Paulo: Associação Brasileira de Cimento Portland, 1985. 8p. BT-111

NBR-06457: Preparação de amostras de solo para ensaio normal de compactação e ensaio de caracterização. Rio de Janeiro: Associação Brasileira de Normas Técnicas, 1984. $3 \mathrm{p}$.

NBR-0659: Solo - determinação do limite de liquidez. Rio de Janeiro: Associação Brasileira de Normas Técnicas, 1984. $3 \mathrm{p}$.

NBR-07180: Solo - determinação do limite de plasticidade. Rio de Janeiro: Associação Brasileira de Normas Técnicas, 1984. $1 \mathrm{p}$.

NBR-07181: Solo - análise granulométrica. Rio de Janeiro: Associação Brasileira de Normas Técnicas, 1984. 13p.

NBR-07182: Solo - ensaio normal de compactação. Rio de Janeiro: Associação Brasileira de Normas Técnicas, 1984. $2 \mathrm{p}$.

NBR-08492: Solo - Cimento - tijolos maciços de solo-cimento: determinação da resistência à compressão e da absorção de água. Rio de Janeiro: Associação Brasileira de Normas Técnicas, 1984. 5p.

NBR-12023: Solo-Cimento - ensaio de compactação. Rio de Janeiro: Associação Brasileira de Normas Técnicas, 1990. $9 \mathrm{p}$.

NBR-12024: Solo-Cimento - moldagem e cura de corpos-deprova_cilíndricos. Rio de Janeiro: Associação Brasileira de Normas Técnicas, 1990.8p.

NBR-12025: Solo-Cimento - ensaio de compressão simples de corpos-de-prova cilíndricos. Rio de Janeiro: Associação Brasileira de Normas Técnicas, 1990.3p.

BARBOSA, N.P; MATTONE, R. Estudo sobre tijolos de terra crua desenvolvidos na Universidade Federal da Paraíba e Politecnico di Torino. In: CONGRESSO DEENGENHARIA CIVIL, II, 1996, Juiz de Fora, MG. Anais, v.1, p. 21-30.
COLLANTES, M.C.; FRANCO, L.S; SABBATINI, F. H. Resistência de aderência ao cisalhamento da alvenaria estrutural não armada de blocos cerâmicos. In: INTERNATIONAL SEMINAR ON STRUCTURAL MASONRY FOR DEVE LOPING COUNTRIES, 5, 1994, Florianópolis, SC. Procee - dings...UFSC/University of Edinburgh/ANTAC, 1994. p. 204-213.

FRANCO, L.S. Desempenho da alvenaria à compressão. São Paulo: USP/POLITÉCNICA, 1988. 14p. BT-20/88

GOBETTI,L.C.W.; WANNI, L.F. \& CAMPAGNOLO, J.L. Análise experimental sobre tijolos cerâmicos maciços e furados fabricados em olarias situadas na Grande Porto Alegre. In: SIMPÓSIO NACIONAL DE TECNOLOGIA DA CONSTRUÇÃO: O USO DA ALVENARIA COMO ESTRUTURA, 1987, São Paulo, SP. Anais. São Paulo: USP/ POLITÉCNICA, 1987.14p.

MATTONE, R.; GOGG. F; PASERO, G. Blocchi in terra stabilizzata: un'esperienza nel nord-est del Brasile. In: WORKSHOP ARQUITETURA DE TERRA, 1995, São Paulo, SP. São Paulo: FAU/USP, 1995. p. 107-113.

NASCIMENTO, A.A.P.; HELENE, P. Estudos de fissuras em paredes de solo-cimento destinadas a edificações habitacionais. São Paulo: USP/POLITÉCNICA, 1988. 26 p. (BT/PCC-108).

PETRUCCI, E.G.R. Materiais de construção. 8.ed. Rio de Janeiro: Globo, 1987.435 p.

SABBATINI, F.H. Argamassa de assentamento para paredes de alvenaria resistente. São Paulo: USP/POLITÉCNICA, 1986. 26 p. (BT02/86)

SOUZA, S.M.T.; MAGALHÃES, M.S.; BARBOSA, N.P. Experimentação de painéis de tijolos prensados de terra crua. In: CONGRESSO DE ENGENHARIA CIVIL, II, 1996, Juiz de Fora, MG. Anais, v.1, 1996. p.11-20. 